Supplement of Ocean Sci., 13, 223-234, 2017

http://www.ocean-sci.net/13/223/2017/

doi:10.5194/os-13-223-2017-supplement

(C) Author(s) 2017. CC Attribution 3.0 License.

(c) (1)

Supplement of

\title{
On the mesoscale monitoring capability of Argo floats in the Mediterranean Sea
}

Antonio Sánchez-Román et al.

Correspondence to: Antonio Sánchez-Román (asanchez@imedea.uib-csic.es)

The copyright of individual parts of the supplement might differ from the CC-BY 3.0 licence. 


\begin{tabular}{|c|c|c|c|c|c|c|}
\hline & \multicolumn{2}{|c|}{$\begin{array}{c}\text { All valid profiles } \\
\text { (DHA ref. 900 dbar) }\end{array}$} & \multicolumn{2}{c|}{$\begin{array}{c}\text { Profiles reaching 900m } \\
\text { (DHA ref. 400 dbar) }\end{array}$} & $\begin{array}{c}\text { All valid profiles } \\
\text { (DHA ref. 400 dbar) }\end{array}$ \\
\hline Argo Floats & \multicolumn{2}{|c|}{8} & \multicolumn{2}{c|}{11} & \multicolumn{2}{c|}{18} \\
\hline Argo Profiles & \multicolumn{2}{|c|}{109} & \multicolumn{2}{c|}{165} & \multicolumn{2}{c|}{996} \\
\hline std (SLA-DHA,cm) & 4.31 & 0.08 & 4.49 & 0.09 & 4.85 & 0.07 \\
\hline R (SLA-DHA) & 0.90 & 0.02 & 0.86 & 0.02 & 0.80 & 0.02 \\
\hline
\end{tabular}

Table S1: Comparison of correlation and standard deviation $(\mathrm{cm})$ of the differences between new AVISO product for the western Mediterranean and Argo data referred to both 400 dbar and $900 \mathrm{dbar}$ (sub-columns on the left). Sub-columns on the right display the results of the robustness experiments in terms of standard deviations (see text for details). DHA referred to $400 \mathrm{dbar}$ has been computed for the whole valid Argo profiles and those reaching $900 \mathrm{~m}$ depth for comparison purposes. The number of Argo platforms and vertical profiles used are also showed.

\begin{tabular}{|c|c|c|c|c|c|c|}
\hline & \multicolumn{2}{|c|}{$\begin{array}{l}\text { All valid profiles } \\
\text { (DHA ref. } 900 \text { dbar) }\end{array}$} & \multicolumn{2}{|c|}{$\begin{array}{l}\text { Profiles reaching } 900 \mathrm{~m} \\
\text { (DHA ref. } 400 \mathrm{dbar} \text { ) }\end{array}$} & \multicolumn{2}{|c|}{$\begin{array}{l}\text { All valid profiles } \\
\text { (DHA ref. } 400 \text { dbar) }\end{array}$} \\
\hline Argo Floats & \multicolumn{2}{|c|}{15} & \multicolumn{2}{|c|}{16} & \multicolumn{2}{|c|}{23} \\
\hline Argo Profiles & \multicolumn{2}{|c|}{307} & \multicolumn{2}{|c|}{314} & \multicolumn{2}{|c|}{1262} \\
\hline std (SLA-DHA,cm) & 5.54 & 0.09 & 5.21 & 0.08 & 4.99 & 0.08 \\
\hline R (SLA-DHA) & 0.71 & 0.02 & 0.71 & 0.02 & 0.70 & 0.02 \\
\hline
\end{tabular}

Table S2: As Table S1 but for the eastern Mediterranean. 